\title{
Sediment Transport Beyond the Surf Zone Under Waves and Currents of the Non-Tidal Sea: Lubiatowo (Poland) Case Study
}

\author{
Rafał Ostrowski, Magdalena Stella \\ Institute of Hydro-Engineering, Polish Academy of Sciences, ul. Kościerska 7, 80-328 Gdańsk, Poland, \\ e-mails: rafal.o@ibwpan.gda.pl,m.stella@ibwpan.gda.pl
}

(Received May 25, 2016; revised June 08, 2016)

\begin{abstract}
The paper deals with the sandy coastal zone at Lubiatowo in Poland (the south Baltic Sea). The study comprises experimental and theoretical investigations of hydrodynamic and lithodynamic processes in the coastal region located close to the seaward boundary of the surf zone and beyond the surf zone. The analysis is based on field data collected at the IBW PAN Coastal Research Station in Lubiatowo. The data consist of wind velocity reconstructed from the long-term wave climate, deep-water wave buoy records and sea bottom soil parameters. Nearbed flow velocities induced by waves and currents, as well as bed shear stresses are theoretically modelled for various conditions to determine sediment motion regimes in the considered area. The paper discusses the possibility of occasional intensive sediment transport and the occurrence of distinct sea bed changes at bigger water depths.
\end{abstract}

Key words: wave-induced nearbed oscillations, sea currents, wind-driven current, sand grain diameter, bed shear stresses, friction velocity, sediment transport

\section{Introduction}

In the surf zone, where the wave breaking phenomena occur, the sea bottom is significantly affected by wave-induced oscillatory flows and wave-driven currents. Here, the wave-current impact on the sea bed causes high rates of sediment transport (even if the sediments consist of coarse sand) with distinct spatial variability, which in turn causes considerable accumulative and erosive processes. At large water depths, the influence of waves and currents on the sandy sea bed is definitely less intensive than in the nearshore region. The sediment motion rates in the offshore areas are much smaller, and the seabed changes become weak. At such locations, the motion of water (and consequently sediment) in the nearbed layer can be related to currents typically occurring in the open sea, for instance, drift currents. In tidal seas, e.g. in the North Sea, the occurrence and movement of large sandy bed forms at depths of $20 \pm 30 \mathrm{~m}$, called sand waves or sand banks, are closely associated with tidal phenomena, see Carbajal \& Montaño (2001) and Hulscher \& van den Brink (2001). Similar large bed 
forms have also been observed, albeit sporadically, in non-tidal realities, namely in the south Baltic coastal areas at depths of 15-30 m, see Rudowski et al (2008).

Open sea currents, such as gradient, geostrophic, inertial and gravitational currents or those arising as a result of seiches, seem to have small impact on sediment transport at the site considered in this study. Recent research carried out by the authors shows that, aside from waves, the wind-driven currents have the most important impact on hydrodynamic processes at a depth of ca. $20 \mathrm{~m}$.

In basins such as the Baltic Sea, the influence of variations in the Coriolis parameter may be neglected, especially at depths considered in this paper. Drift current occurring in shallow basins and coastal waters has almost the same direction in the water column as the wind blowing over the water surface. Because the surface Ekman layer and the bottom Ekman layer overlap, the development of the Ekman Spiral is hindered, and the wind-induced transport takes place in the wind direction (Krauss 2001, Trzeciak 2000, Valle-Levinson 2016). The present paper deals with the wind-driven currents occurring locally and temporarily. Hence, the wind-driven current velocity profile can be described by a directionally invariable distribution.

Certainly, wave-induced orbital nearbed velocities have some impact on the sea bottom also beyond the surf zone. A seaward boundary of this influence is conventionally related to a so-called depth of closure $\left(h_{c}\right)$, at which even stormy waves do not cause intensive sediment transport (a so-called sheet flow). The corresponding extreme wave conditions are most often represented by the "effective" significant wave height $\left(H_{e}\right)$, as that is exceeded only 12 hours per year, or $0.137 \%$ of the time. Simple formulas derived by Birkemeier (1985), or earlier by Hallermeier $(1978,1981)$, for the assessment of the depth of closure $h_{c}$ from the effective significant wave height $\left(H_{e}\right)$ and period $\left(T_{e}\right)$, are discussed e.g. by Dean (2002). On a second front, the depth of closure $h_{c}$ can be determined directly from bathymetric changes if only sufficient data are available.

The results of recent research on the depth of closure for the multi-bar shore, characteristic of the south Baltic Sea, were presented by Cerkowniak et al (2015a), who obtained actual values of the depth of closure (determined from bathymetric surveys) $h_{c}=6.0-7.7 \mathrm{~m}$, greater than the ones calculated using parameters of the effective significant wave height $\left(h_{c}=4.9-6.5 \mathrm{~m}\right)$. The findings of Cerkowniak et al (2015b) indicate that the wave-induced bed shear stresses during heavy storms (with the deep water significant wave height $H_{s}$ exceeding $3.5 \mathrm{~m}$ ) can cause intensive sediment transport (sheet flow) even at depths of 13-15 $\mathrm{m}$. Such wave conditions, however, last no longer than one day and night per year, and probably cannot, by themselves, cause distinct changes of sea bottom, leading to the appearance and movement of large offshore bed forms, similar to bars. According to Cerkowniak et al (2015b), even during extreme storms, sheet flow is unlikely to happen at water depths greater than $15 \mathrm{~m}$, and large bed forms in this region can probably appear and evolve only if stormy waves are accompanied by strong sea currents. 
The above considerations give rise to a hypothesis about an important role of currents typically occurring beyond the surf zone and interacting with wave-induced oscillatory flows. Under storm conditions, this interaction presumably generates bed shear stresses sufficient to cause intensive sediment transport and, consequently, distinct sea bottom evolution.

Verification of the above hypothesis requires a precise determination of the sediment motion driving forces (bed shear stresses) resulting from the interaction of nearbed wave-induced oscillations (orbital velocities) with steady currents occurring during severe storms at the seaward boundary of the surf zone and beyond the surf zone.

The present study tackles this issue by the theoretical modelling of the bottom shear stresses generated by extreme wave-current conditions beyond the surf zone.

\section{Study Site and Data}

The measurements were carried out at the IBW PAN Coastal Research Station (CRS) near Lubiatowo. The study area of CRS Lubiatowo is situated about $70 \mathrm{~km} \mathrm{NW}$ of Gdańsk (see Figure 1), with a laboratory building at the coordinates $54^{\circ} 48^{\prime} 42.0^{\prime \prime} \mathrm{N}$ $17^{\circ} 50^{\prime} 25.6^{\prime \prime} \mathrm{E}$. It is a typical south Baltic sandy coast. Field surveys conducted at Lubiatowo comprise coastal hydrodynamics, lithodynamics and morphodynamics (see Ostrowski et al 2015). For purposes of the present study, offshore wave buoy data were used, as well as results of sea bed soil sampling and grain size analysis.

The sea shore near Lubiatowo is mildly sloped (with an inclination of 1-2\%) and consists of quartz sand having the median grain diameter $d_{50}$ lying in the range from 0.1 to $0.4 \mathrm{~mm}$ (mostly $0.15-0.25 \mathrm{~mm}$ ). The seabed soil density amounts to $\rho_{s}=2650$ $\mathrm{kg} / \mathrm{m}^{3}$. Cross-shore bathymetric profiles display 3-4 stable bars and an additional, ephemeral one occurring close to the shoreline. Such a multi-bar profile of the sea bottom is favourable to gradual wave energy dissipation, taking place by multiple wave breaking, see Pruszak et al (2008).

The offshore wave measurements at CRS Lubiatowo have been carried out since 1990s by means of directional wave buoys ("Directional Waverider Buoys") produced by the Dutch company Datawell BV, namely Waverider Mk. II and DWR-7 Mk. III (see Fig. 2).

Since 2001, the wave buoys have been moored at locations where water depth amounts to $15-18 \mathrm{~m}$, described approximately by coordinates $54^{\circ} 50^{\prime} \mathrm{N}$ and $17^{\circ} 50^{\prime}$ $\mathrm{E}$, at a distance of about 1.0-1.5 Nm (i.e. $1.85-2.78 \mathrm{~km}$ ) from the shoreline. Wave data are transmitted by radio from the buoy to the receiver located in the laboratory room of the CRS Lubiatowo building. Both raw and processed wave data are also stored in the buoy logger. Access to the logger is possible after the withdrawal of the wave buoy from the sea. 


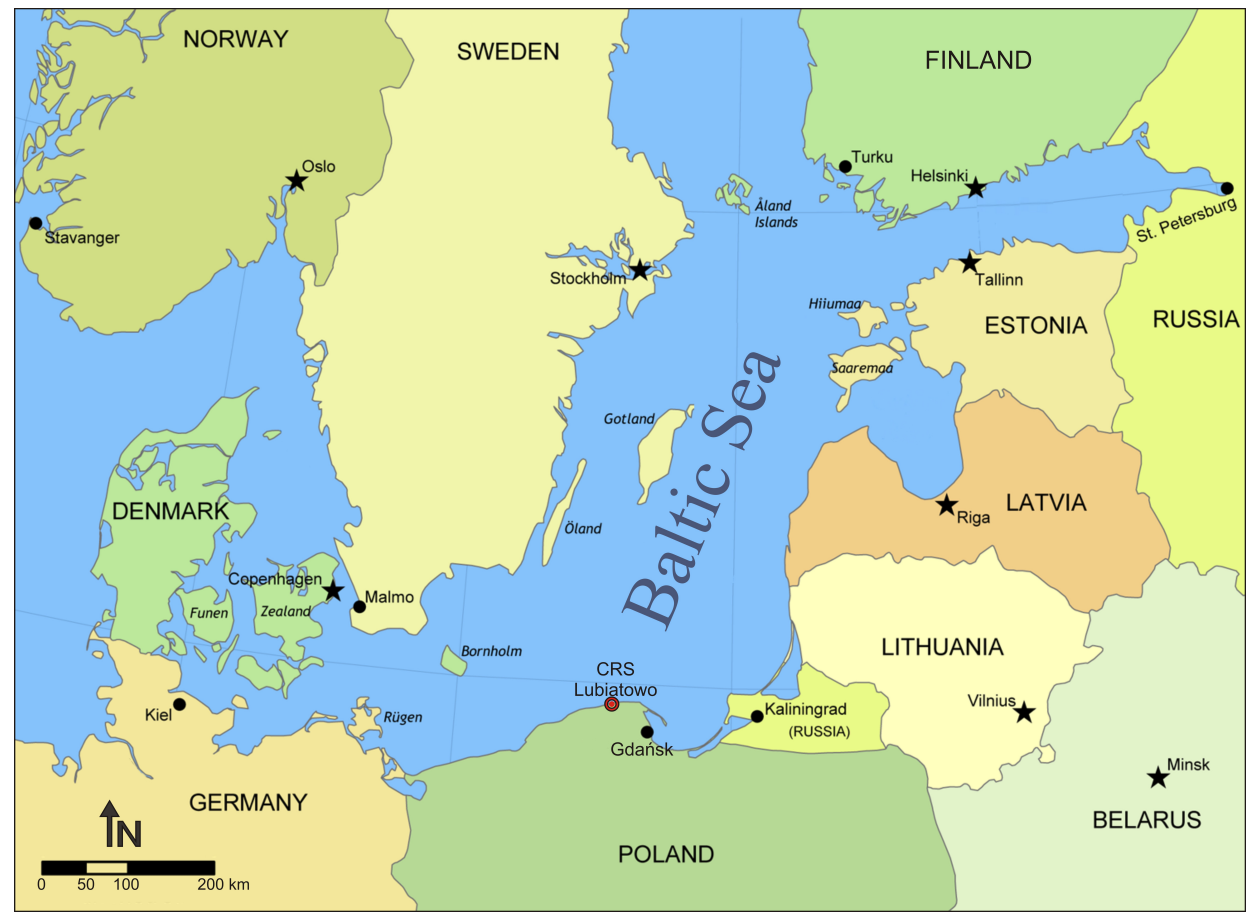

Fig. 1. Location of CRS Lubiatowo on the Baltic coast

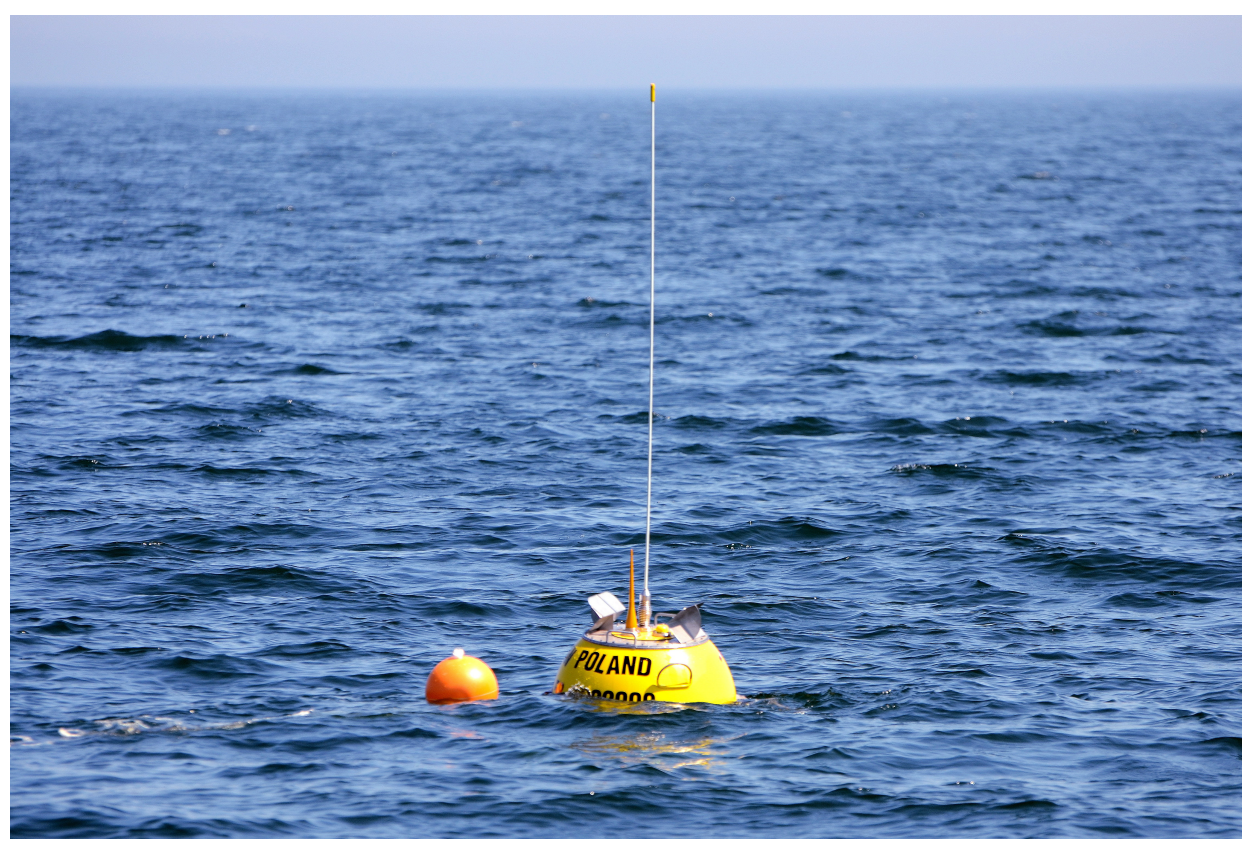

Fig. 2. Wave buoy DWR-7 Mk. III 


\section{Method of Analysis}

The investigations were focused on determining whether the motion of sediments beyond the surf zone is possible and what intensity it can have. Recent deep-water wave data (since 2010) have been recorded at a location where the water depth amounts to $18 \mathrm{~m}$, about $1.5 \mathrm{Nm}$ from the shoreline. The wave parameters measured at this point constitute a basis for the determination of wave-induced nearbed oscillatory currents under extreme stormy conditions.

In order to verify the possibility of sediment motion at a depth of $18 \mathrm{~m}$, the bed shear stresses were calculated for the following cases:

1. wave-induced nearbed oscillatory flow with the bottom roughness of sand grains (so-called "skin" bed roughness, as defined by Nielsen 2009);

2. wave-induced nearbed oscillatory flow with the overall bottom roughness (so-called "equivalent" moveable bed roughness, as defined by Kaczmarek 1995, 1999);

3. nearbed stationary flow caused by the wind-driven current, with the "skin" bed roughness and the roughness resulting from the presence of bed forms of various heights;

4. nearbed flow caused by the wind-driven current superimposed on wave-induced nearbed oscillations, with the overall bottom roughness ("equivalent" moveable bed roughness).

Sediment transport intensity is conventionally estimated by using the Shields parameter, which represents the dimensionless bed shear stress and is given by the following formula (see e.g. Nielsen 2009):

$$
\theta=\frac{u_{f}^{2}}{(s-1) g d}
$$

in which $u_{f}=$ the friction velocity, $s=$ the ratio of seabed soil density $\rho_{s}$ to water density $\rho\left(s=\rho_{s} / \rho\right.$, for quartz sand equal to about 2.65), $g=$ acceleration due to gravity, and $d=$ seabed grain diameter.

The reliable and precise determination of the friction velocity $u_{f}$ is difficult, particularly for unsteady currents, e.g. wave-induced nearbed oscillatory flows. The friction velocity represents the bed shear stress $\tau$ (defined as $\tau=\rho u_{f}^{2}$ ), which is the main driving force for sediment transport. According to the basics of fluid mechanics, the bed shear stress $\tau$ depends on the water flow velocity and the sea bottom roughness. The seabed, if built of sandy sediments, becomes moveable under hydrodynamic impacts (resulting from turbulent water flow generated by waves and currents), which causes additional difficulties in a theoretical solution leading to the determination of the friction velocity $u_{f}$. In the present study, various theoretical approaches are applied to particular cases.

The dimensionless shear stress depends on the grain diameter $d$. Soil sampling and analyses show that the sand occurring at the study site (water depth $h=18 \mathrm{~m}$ ) is very 
fine. The present analysis was carried out for two sand grain diameters: $d=0.0001$ $\mathrm{m}$ and $d=0.00015 \mathrm{~m}$ (i.e. 0.1 and $0.15 \mathrm{~mm}$, respectively).

\subsection{Wave and Wind Parameters}

As deduced by Kaczmarek \& Ostrowski $(1995,1996)$, bed shear stresses and sediment transport rates under natural conditions (for irregular waves, actually observed at sea) can be reliably modelled by the linear wave theory, using the root-mean-square wave height $\left(H_{r m s}\right)$ and the wave energy peak period $\left(T_{p}\right)$ as inputs. Therefore, the bed shear stresses generated by waves and wave-current interactions were computed using the wave parameters $H_{r m s}$ and $T_{p}$.

The extreme wave conditions at a depth of $h=18 \mathrm{~m}$ were assumed as the "effective" wave height (exceeded only 12 hours per year, or $0.137 \%$ of the time) and the corresponding wave energy peak period. From the analysis of the deep-water data base records since 2011, the following values have been obtained:

$$
H_{r m s}=2.68 \mathrm{~m}, \quad T_{p}=9.09 \mathrm{~s} .
$$

The extreme wind velocity was determined analogically to the extreme wave height, i.e. as the velocity exceeded only 12 hours per year, or $0.137 \%$ of the time. The wind velocity (at a height of $10 \mathrm{~m}$ above the sea) was determined from the results of the HIPOCAS project, aimed at reconstructing 44 years of European wind-wave climate. A detailed description of the reconstruction procedure is given in Weisse et al (2009). The available wind reconstruction point closest to the site where wave measurements were carried out, lies at coordinates $54^{\circ} 54^{\prime} 44.64^{\prime \prime} \mathrm{N}$ and $18^{\circ} 17^{\prime} 7.8^{\prime \prime} \mathrm{E}$ (about $4 \mathrm{Nm}$ northwards and $12 \mathrm{Nm}$ eastwards from the recent location of the wave buoy). Based on the data obtained from the HIPOCAS project, the "effective" wind velocity value at the selected point amounts to

$$
w=14.6 \mathrm{~m} / \mathrm{s} .
$$

The above quantities $\left(h, H_{r m s}, T_{p}\right.$ and $\left.w\right)$ were used in the theoretical modelling of the bed shear stresses under various hydrodynamic impacts.

\subsection{Wave-Induced Bed shear Stress with "Skin” bottom Roughness}

In the case of bed shear stress generated by waves on the flat sea bottom, according to Nielsen (2009), it is advisable to use an approach which deals with the wave-related bed roughness concerning sand grains only ("skin" bed roughness) and to neglect bed roughness resulting from the presence of bed forms (ripple bed roughness). Such an assumption is justified both for a flat bed or weakly developed bottom ripples (sediment motion of small intensity) and for very intensive sediment transport during which the bed forms are washed away (sheet flow). The dimensionless bed shear stress 
for the situation of "skin" bottom friction, related to a "skin" roughness height of $2.5 \mathrm{~d}$, can be determined by the following equation (Nielsen 2009):

$$
\theta_{2.5}=\frac{1}{2} f_{2.5} \frac{\left(a_{1 m} \omega\right)^{2}}{(s-1) g d}
$$

in which:

$$
f_{2.5}=\exp \left[5.5\left(\frac{2.5 d}{a_{1 m}}\right)^{0.2}-6.3\right],
$$

where $\omega$ denotes angular frequency in the wave motion, $a_{1 m}=U_{1 m} / \omega$ (amplitude of the nearbed oscillatory flow), and $U_{1 m}$ is the maximum nearbed wave-induced (free stream) oscillatory velocity (for sinusoidal waves, $U(\omega t)=U_{1 m} \sin (\omega t)$ ).

The value $\theta_{2.5}=0.05$ is usually assumed as a condition for the initial motion of single grains. A more intensive motion of seabed grains and developed bottom ripples are observed for $\theta_{2.5}$ equal to $0.2-0.3$. Under considerably intensive hydrodynamic impacts, characterised by $\theta_{2.5}$ amounting to $0.8-1.0$, ripple marks are washed away, and sheet flow occurs.

\subsection{Wave-Induced Bed Shear Stress with "Equivalent" Bottom Roughness}

In the case of shear stresses triggered over an arbitrarily shaped sea bottom by wave-induced oscillatory nearbed flows, the approach proposed by Kaczmarek (1995) was used. Within this approach, the velocity distribution in the bed boundary layer (the bedload layer and the "buffer" layer between the bedload and the suspended load layers) was determined by parameters depending on the geometric roughness properties of the bed and outer flow parameters, such as the free-stream wave velocity (nearbed oscillatory flow). The iterative procedure elaborated by Kaczmarek (1995) ensured the determination of the "equivalent" moveable bed roughness height $k_{e}$. This parameter comprises the overall roughness represented by the sand grains building the bottom and the effects of bedload. Further development of this concept by Kaczmarek (1999) led to the formulation of approximate equations describing the roughness height $k_{e}$ as functions of the Shields parameter.

The sediment transport model developed by Kaczmarek \& Ostrowski (2002) was based on a three-layer scheme. The sediment was assumed to move as bedload, high-concentration suspended load close to the bottom (in a so-called contact load layer or transitional layer) and low-concentration suspended load in the water column (beyond the bed boundary layer). The modelling system was based on the bed shear stresses $\tau=\rho u_{f}^{2}$ as the prime mover of sediment transport. The time-variable friction velocity $u_{f}(t)$ was determined by the integral momentum method of Fredsøe (1984). This approach has been adopted in the present study. 


\subsection{Bed Sshear Stress Induced by Wind-Driven Current}

The shear stresses $\tau$ in the water column where the wind-driven current occurs are assumed to satisfy the Boussinesq hypothesis as follows:

$$
\tau=\rho v_{t} \frac{d u}{d z},
$$

where $v_{t}$ is the kinematic turbulent viscosity $\left[\mathrm{m}^{2} / \mathrm{s}\right]$ in the vertical direction, and $u(z)$ is the velocity of stationary water flow.

It is further assumed that the turbulent viscosity increases linearly from the bottom, being proportional to von Karman's constant $\kappa$ and the friction velocity $u_{f}$, so that

$$
v_{t}=\kappa u_{f} z
$$

Bearing in mind the shear stress defined as $\tau=\rho u_{f}^{2}$, one obtains the logarithmic vertical distribution of velocity $u(z)$ :

$$
u(z)=\frac{u_{f}}{\kappa} \ln \left(\frac{z}{z_{0}}\right),
$$

in which $z_{0}$ denotes the ordinate, at which the velocity $u$ equals zero.

The quantity $z_{0}$ can be regarded as a theoretical sea bed level from which the logarithmic profile of the velocity $u(z)$ starts. Conventionally, this level is determined as $z_{0}=k_{N} / 30$, where $k_{N}$ is a so-called Nikuradse roughness. The assumption of the bottom characterised by a "skin" roughness height of $2.5 d$ (related to the presence of sand grains only, see the approach presented in section 3.2) yields $z_{0}=2.5 d / 30$. If the sea bottom is covered by bed forms, the bottom roughness height will be $z_{0}=k_{f} / 30$, where $k_{f}$ is the bed form height.

With the assumed bed roughness and with the resulting value of $z_{0}$, one can easily determine the friction velocity $u_{f}$ from Eq. (6) if only the flow velocity $u$ at any level $z$ is known. Sometimes, however, the mean flow velocity $u_{\text {mean }}$ is available (averaged over the water column). In such a case, it is necessary to take advantage of the logarithmic velocity distribution integrated over the water depth $h$, from the theoretical bed level $z_{0}$ to the water surface level. After integration of the logarithmic distribution of $u(z)$, division by the water depth $h$ and rearrangement, the following formula for the friction velocity $u_{f}$ is obtained:

$$
u_{f}=\frac{\kappa u_{\text {mean }}}{\ln \left(\frac{h}{z_{0}}\right)-1+\frac{z_{0}}{h}} .
$$

Within the present study, however, as no data concerning the steady current are available, the wind-driven flow velocity at the surface inertial sublayer (from the still water level to $1 \mathrm{~m}$ depth) is calculated by Eq. (8). This formula is based on the assumption that the wind-driven current speed in the inertial sublayer equals $2-5 \%$ of 
the wind speed $w$ at the $10 \mathrm{~m}$ height above the sea level (see e.g. Kim et al, 2010). In this study, the authors are considering extreme cases, hence the magnitude of the surface current is assumed to be $5 \%$ of the wind speed:

$$
u(0<z<h-1)=0.05 w .
$$

The above velocity is next assumed to satisfy the logarithmic distribution given by Eq. (6) and used in calculating the friction velocity $u_{f}$ from this equation.

\subsection{Bed Shear Stress Induced by Nearbed Wave-Current Interaction}

Developed by Kaczmarek \& Ostrowski (2002), the model of intensive near-bed sand transport under wave-current flow provided reliable values of sediment transport rates, successfully verified against laboratory and field data. In this model, as mentioned previously (see section 3.3), the shear stress induced over the sea bottom characterised by the "equivalent" roughness of the moveable bed was the driving force of sediment movement. This approach was later applied by Ostrowski $(2003,2004)$ in the modelling of wave transformation, wave-driven currents, net sand transport and short-term morphodynamics of a multi-bar coastal zone.

For purposes of the present research, the abovementioned modelling framework has been adapted to the case of the open sea (beyond the surf zone), where wave propagation under storm conditions is accompanied by the influence of a strong wind-driven current. To include this effect, the dispersion relationship for wave motion interacting with a steady flow, represented by the mean wind-driven current velocity $u_{\text {mean }}$, is used:

$$
g k \tanh k h=\left(\omega-k u_{\text {mean }} \cos \alpha\right)^{2},
$$

where $k=2 \pi / L$ is the wave number ( $L$ stands for the wave length), and $\alpha$ denotes the angle between the steady flow velocity $u_{\text {mean }}$ and the wave propagation direction.

It should be noted that an additional hydrodynamic effect appears if the wave motion is superimposed on the stationary flow, namely the apparent bottom roughness: the flow above the wave boundary layer encounters larger roughness due to the occurrence of waves (see e.g. Nielsen 2009). This effect is taken into account in the present study by including the apparent bottom roughness $k_{a}$ in the steady flow model as follows:

$$
\begin{gathered}
u(z)=\frac{u_{f c}}{\kappa} \ln \left(\frac{30 z}{k_{a}}\right), \\
u_{\text {mean }}=\frac{u_{f c}}{\kappa}\left[\ln \left(\frac{30 h}{k_{a}}\right)-1+\frac{k_{a}}{30 h}\right] .
\end{gathered}
$$


In the above equations, the friction velocity $u_{f c}$ represents the influence of the wave bed boundary layer and is calculated from the values of the wave-induced friction velocity $u_{f}(t)$ according to the following formula (see Ostrowski 2004):

$$
u_{f c}=\sqrt{\frac{1}{T} \int_{0}^{T}\left|u_{f}(t)\right| u_{f}(t) \cos \phi(t) d \omega t},
$$

where $\cos \phi(t)$ is an instantaneous angle between the steady current and direction of wave-induced nearbed oscillatory flow during the wave period $T$.

Similarly as in the case of wave-induced bed shear stresses (cf. section 3.3), the time-variable friction velocity $u_{f}$ for the bed shear stresses generated jointly by waves and the wind-driven current is determined using the theoretical concept of Kaczmarek \& Ostrowski (2002).

\section{Results and Discussion}

The modelling of the bed shear stresses was run with the input quantities given in section 3.1 for the hydrodynamic cases described in sections 3.2-3.5. For the case of bed shear stresses induced solely by the wind-driven current (described in section 3.4 ), aside from the "skin" bed roughness $\left(k_{N}=2.5 d\right)$, two values of the bed form roughness were assumed, namely $k_{f}=0.05 \mathrm{~m}$ and $k_{f}=0.10 \mathrm{~m}$.

The computations of the dimensionless shear stress (Shields parameter) $\theta$ with the assumed "skin" bed roughness (see sections 3.2 and 3.4) were carried out for the sand grain diameters $d=0.1 \mathrm{~mm}$ and $d=0.15 \mathrm{~mm}$, actually occurring at the considered site. For the cases of the wave-induced shear stress and the shear stress induced by waves and currents (described in sections 3.3 and 3.5, respectively), the Shields parameter $\theta_{\max }$ was calculated from the friction velocity $u_{f \max }=\max \left[u_{f}(\omega t)\right]$. The wave-current case (section 3.5) was solved for the co-linear propagation of waves and the wind-driven current. The results of modelling are given in Tables 1-4.

In analysing the results of $\theta$ computations, the following regimes of sediment transport were assumed:

$\theta \in\langle 0 ; 0.05\rangle \quad$ no sediment motion;

$\theta \in(0.05 ; 0.3\rangle \quad$ very weak sediment motion; ripples appear on the seabed;

$\theta \in(0.3 ; 0.6\rangle \quad$ weak sediment motion; ripples develop;

$\theta \in(0.6 ; 0.9\rangle \quad$ moderately intensive sediment motion; ripple height decreases;

$\theta>0.9 \quad$ intensive sediment motion (sheet flow), flat seabed.

The results of calculations shown in Table 1 (dimensionless wave-induced bed shear stress $\theta_{2.5}$ with the "skin" bottom roughness) indicate that, under extreme stormy wave conditions, sea bed grains with a diameter of $0.1 \mathrm{~mm}$ are subject to rather intense motion and that ripple marks can be washed out. Coarser sand grains $(d=0.15 \mathrm{~mm})$ 
Table 1. Wave-induced bed shear stress with "skin" bottom roughness

\begin{tabular}{|c|c|c|}
\hline & $d=0.1 \mathrm{~mm}$ & $d=0.15 \mathrm{~mm}$ \\
\hline$U_{1 m}$ & 0.696 & 0.696 \\
\hline$\theta_{2.5}$ & 0.782 & 0.570 \\
\hline
\end{tabular}

Table 2. Wave-induced bed shear stress with "equivalent" bottom roughnes

\begin{tabular}{|c|c|c|}
\hline & $d=0.1 \mathrm{~mm}$ & $d=0.15 \mathrm{~mm}$ \\
\hline$u_{f \max }$ & 0.056 & 0.062 \\
\hline$\theta_{\max }$ & 1.92 & 1.56 \\
\hline
\end{tabular}

Table 3a. Bed shear stress induced by wind-driven current for $d=0.1 \mathrm{~mm}$

\begin{tabular}{|c|c|c|c|}
\hline & $k_{N}=2.5 d$ & $k_{N}=k_{f}=0.05 \mathrm{~m}$ & $k_{N}=k_{f}=0.1 \mathrm{~m}$ \\
\hline$u_{\text {mean }}$ & 0.680 & 0.655 & 0.649 \\
\hline$u_{f}$ & 0.020 & 0.032 & 0.034 \\
\hline$\theta$ & 0.265 & 0.660 & 0.771 \\
\hline
\end{tabular}

Table 3b. Bed shear stress induced by wind-driven current for $d=0.15 \mathrm{~mm}$

\begin{tabular}{|c|c|c|c|}
\hline & $k_{N}=2.5 d$ & $k_{N}=k_{f}=0.05 \mathrm{~m}$ & $k_{N}=k_{f}=0.1 \mathrm{~m}$ \\
\hline$u_{\text {mean }}$ & 0.679 & 0.655 & 0.649 \\
\hline$u_{f}$ & 0.021 & 0.032 & 0.034 \\
\hline$\theta$ & 0.187 & 0.440 & 0.514 \\
\hline
\end{tabular}

Table 4. Bed shear stress induced by nearbed wave-current interaction

\begin{tabular}{|c|c|c|c|}
\hline & $k_{N}=2.5 d$ & $k_{N}=k_{f}=0.05 \mathrm{~m}$ & $k_{N}=k_{f}=0.1 \mathrm{~m}$ \\
\hline \multicolumn{3}{|c|}{$d=0.1 \mathrm{~mm}$} \\
\hline$u_{f c}$ & 0.030233 & 0.029428 & 0.029234 \\
\hline$u_{f \max }$ & 0.067987 & 0.067319 & 0.067161 \\
\hline$\theta_{\max }$ & 2.856805 & 2.800906 & 2.787759 \\
\hline \multicolumn{3}{|c|}{$d=0.15 \mathrm{~mm}$} \\
\hline$u_{f c}$ & 0.032003 & 0.031190 & 0.030986 \\
\hline$u_{f \max }$ & 0.073895 & 0.073247 & 0.073086 \\
\hline$\theta_{\max }$ & 2.249911 & 2.210590 & 2.200930 \\
\hline
\end{tabular}


move in the ripple regime (less intensively) under the same wave conditions. Analogous modelling with the assumed "equivalent" bottom roughness yields (Tab. 2) a much more intense regime of sediment transport ( $\theta_{\max }$ amounting to 1.92 and 1.56 for $d=0.1 \mathrm{~mm}$ and $d=0.15 \mathrm{~mm}$, respectively, indicate sheet flow and a flat sea bed). Dimensionless bed shear stresses $\theta$ determined for the case of the sole wind-driven current under extreme stormy conditions (Tab. 3a and 3b), in comparison with the extreme stormy wave-induced hydrodynamics (Tables 1 and 2), are distinctly smaller for all assumed bed roughness values.

The most interesting case is represented by the nearbed wave-current interaction. Shown in Tab. 4, the results of the modelling of the dimensionless bed shear stresses $\theta_{\max }$ generated by waves and the wind-driven current indicate that the sandy material under the considered conditions and at the considered site is subject to very intense movement. Further, it appears that the values of $\theta_{\max }$ given in Tab. 4 are higher than the sums of their counterparts $\left(\theta_{\max }\right.$ and $\left.\theta\right)$ given in Tables $2,3 \mathrm{a}$ and $3 \mathrm{~b}$. This nonlinear effect clearly implies a synergic character of wave-current interaction as a prime mover of marine lithodynamics.

It is worth noting that the values of $u_{f c}, u_{f \max }$ and $\theta_{\max }$ shown in Table 4 are little dependent on the bed roughness $k_{N}$. This is typical of the wave-dominated bed boundary layer, which is weakly affected by the steady current. On the other hand, the steady current is significantly affected by the wave-dominated bed boundary layer constituting a larger apparent bottom roughness (see discussion on this issue in section $3.5)$.

\section{Final Remarks and Conclusions}

According to Nielsen (2009), rapidly accelerated flows induced by waves have thinner bed boundary layers than longer period flows (like tidal currents). Consequently, wave motions generate greater bed shear stresses for a given free stream velocity magnitude. This rule is confirmed by the results obtained in the present study. The bed shear stresses determined for the wave-induced oscillatory flow are much bigger than the ones determined for the wind-driven steady current although the free stream velocities in the above cases are similar. According to the Boussinesq hypothesis, expressed in Eq. (4), the bed shear stress depends on the velocity derivative $(d u / d z)$ in the bed boundary layer. The wave boundary layer has a thickness of the order of a few centimetres and is "invisible" in comparison to the boundary layer associated with the steady flow. This is depicted by computational results shown in Fig. 3.

For the site considered, the modelling of bed shear stresses for various extreme hydrodynamic impacts yields the highest values of the Shields parameter $\theta$ in the case of a joint action of waves and the wind-driven current. It appears that the nonlinear wave-current interaction generates bed shear stresses bigger than would result from the superposition of results determined separately for the impacts of waves and cur- 


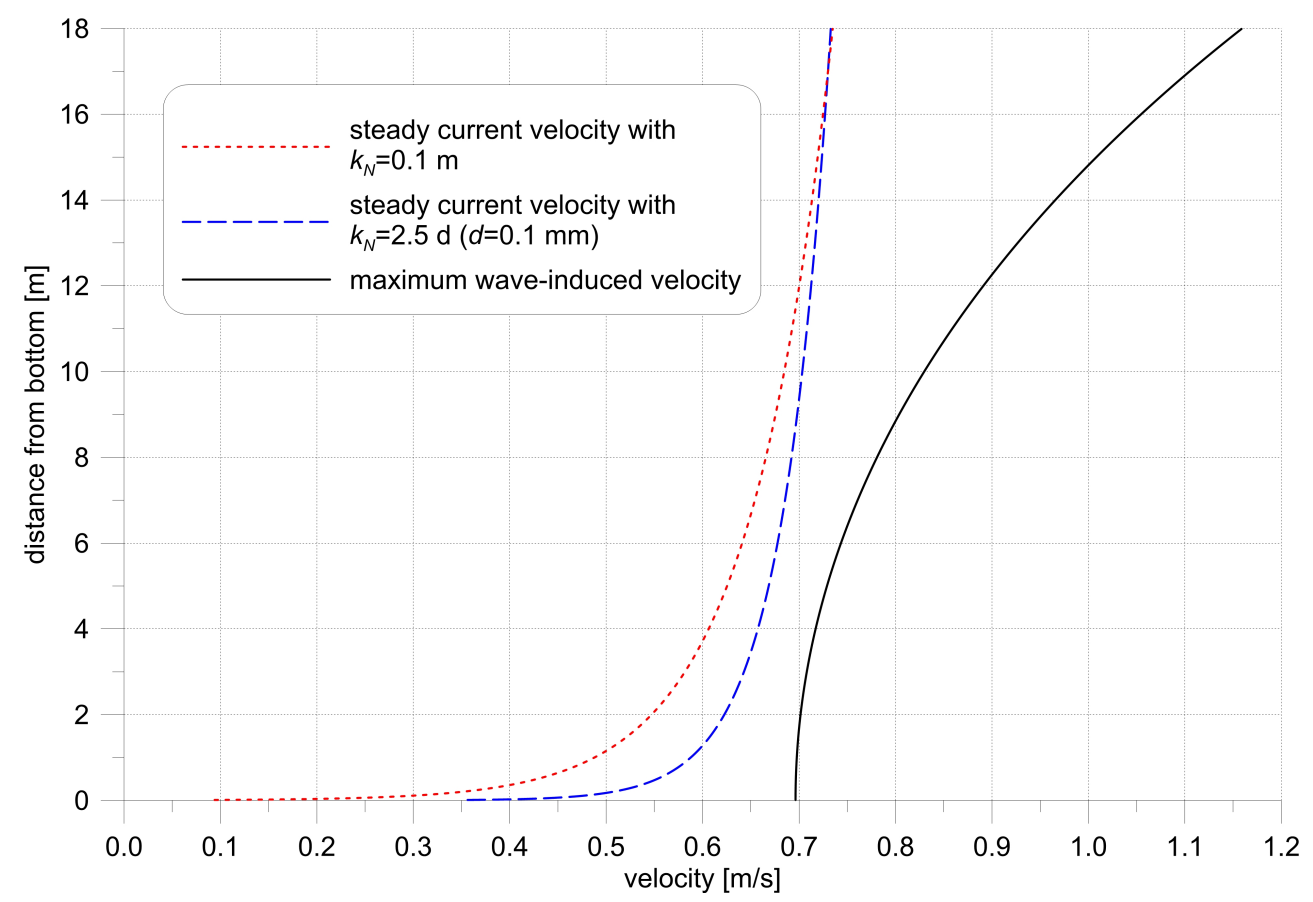

Fig. 3. Velocity profiles of steady wind-driven currents and wave-induced oscillatory flow

rents. The calculated bed shear stresses are high enough to generate intensive sediment transport.

The hydrodynamic conditions assumed at a depth of $18 \mathrm{~m}$, however, have an instantaneous character in the scale of a year, as they occur for 12 hours only. A question arises whether such a short duration of these conditions can justify the appearance and migration of bed forms, especially large forms, like sand waves. It can be supposed that the significant sea bed changes observed (Rudowski et al, 2008) result from extreme wave-current conditions occurring repeatedly in longer time scales, e.g. during a few years. Clarification of the above doubts requires a more detailed quantitative insight into steady currents present beyond the surf zone. In particular, measurements of nearbed velocities at a depth of 18-20 m would shed new light on the hydrodynamic and lithodynamic processes taking place in this region.

\section{Acknowledgements}

The study was sponsored by the Ministry of Science and Higher Education, Poland, under mission-related programme No. 2 of IBW PAN. The Authors wish to thank Professor Zbigniew Pruszak for his helpful comments on an earlier version of this manuscript. 


\section{References}

Birkemeier W. A. (1985) Field data on seaward limit of profile change, Journal of Waterway, Port, Coastal and Ocean Engineering 3, 598-602.

Carbajal N., Montaño Y. (2001) Comparison between Predicted and Observed Physical Features of Sandbanks. Estuarine, Coastal and Shelf Science, 52, 435-443.

Cerkowniak G. R., Ostrowski R., Stella M. (2015a) Depth of closure in the multi-bar non-tidal nearshore zone of the Baltic Sea: Lubiatowo (Poland) case study, Bulletin of the Maritime Institute in Gdańsk, 30, (1), 180-188.

Cerkowniak G. R., Ostrowski R., Stella M. (2015b) Wave-Induced Sediment Motion Beyond the Surf Zone: Case Study of Lubiatowo (Poland), Archives of Hydro-Engineering and Environmental Mechanics, 62, (1-2), 27-39.

Dean R. G. (2002) Beach Nourishment. Theory and Practice, Advanced Series on Ocean Engineering - Volume 18. World Scientific Publishing Co. Pte. Ltd., 399 pp.

Fredsøe J. (1984) Turbulent boundary layer in combined wave-current motion, J. Hydraulic Eng., ASCE, 110, (HY8), 1103-1120.

Hallermeier R. J. (1978) Uses for a calculated limit depth to beach erosion, Proceedings, 16th Coastal Engineering Conference, American Society of Civil Engineers, 1493-1512.

Hallermeier R. J. (1981) A profile zonation for seasonal sand beaches from wave climate, Coastal Engineering 4, 253-277.

Hulscher S. J. M. H., van den Brink G. M. (2001) Comparison between predicted and observed sand waves and sand banks in the North Sea, Journal of Geophysical Research, 106 (C5), 9327-9338.

Kaczmarek L. M. (1995) Nonlinear effects of waves and currents on moveable bed roughness and friction, Archives of Hydro-Engineering and Environmental Mechanics, 42, (1-2), 3-27.

Kaczmarek L. M. (1999) Moveable Sea Bed Boundary Layer and Mechanics of Sediment Transport, DSc Thesis, IBW PAN, Gdańsk, ISBN 83-85708-35-9, 209 pp.

Kaczmarek L. M., Ostrowski R. (1995) Modelling of Bed Shear Stress under Irregular Waves, Archives of Hydro-Engineering and Environmental Mechanics, 42, (1-2), 29-51.

Kaczmarek L. M., Ostrowski R. (1996) Bedload Under Asymmetric and Irregular Waves: Theory Versus Laboratory Data, Archives of Hydro-Engineering and Environmental Mechanics, 43, (1-4), 21-42.

Kaczmarek L. M., Ostrowski R. (2002) Modelling intensive near-bed sand transport under wave-current flow versus laboratory and field data, Coastal Engineering, Elsevier Science B.V., 45, (1). 1, 1-18.

Kim S. Y., Cornuelle B. D., Terrill E. J. (2010) Decomposing observations of high-frequency radar derived surface currents by their forcing mechanisms: Locally wind-driven surface currents, Journal of Geophysical Research, 115, C12046, doi:10.1029/2010JC006223.

Krauss W. (2001) Baltic sea circulation, doi:10.1006/rwos.2001.0381.

Nielsen P. (2009) Coastal and Estuarine Processes, Advanced Series on Ocean Engineering - Volume 29, World Scientific Publishing Co. Pte. Ltd., 343 pp.

Ostrowski R. (2003) A quasi phase-resolving model of net sand transport and short-term cross-shore profile evolution, Oceanologia, 45, (2), 261-282.

Ostrowski R. (2004) Morphodynamics of a Multi-Bar Coastal Zone, DSc Thesis, IBW PAN, Gdańsk, ISBN 83-85708-64-2, 163 pp.

Ostrowski R., Schönhofer J., Szmytkiewicz P. (2015) South Baltic representative coastal field surveys, including monitoring at the Coastal Research Station in Lubiatowo, Poland, Journal of Marine Systems, Elsevier Science B.V., doi:10.1016/j.jmarsys.2015.10.006.

Pruszak Z., Szmytkiewicz P., Ostrowski R., Skaja M., Szmytkiewicz M. (2008) Shallow-water wave energy dissipation in a multi-bar coastal zone, Oceanologia, 50 (1), 43-58. 
Rudowski S., Łęczyński L., Gajewski Ł. (2008) Sand waves on the bottom of the deep coastal zone and their impact on the sea shore, Landform Analysis, 9, 214-216 (in Polish).

Trzeciak S. (2000) Marine Meteorology with Oceanography, Wydawnictwo Naukowe PWN, 249 pp. (in Polish).

Weisse R., von Storch H., Callies U., Chrastansky A., Feser F., Grabemann I., Günther H., Plüss A., Stoye T., Tellkamp J., Winterfeldt J., Woth K. (2009) Regional meteorological-marine reanalyses and climate change projections. Results for Northern Europe and potential for coastal and offshore applications, Bull. Amer. Meteor. Soc., 90, (6), 849-860.

Valle-Levinson A. (2016, 05 31) Lecture 13. Equations of Motion, web location: www.essie.ufl.edu/ arnoldo. 